\title{
Maternal high-fat diet during pregnancy or lactation changes the somatic and neurological development of the offspring
}

\author{
Dieta materna rica em gordura durante a gravidez ou lactação altera o \\ desenvolvimento somático e neurológico da prole \\ Cristiano Mendes-da-Silva', Catherine Ássuka Giriko 1,2, Laís Vales Mennitti1,2, Lilian Fazion Hosoume', \\ Tayane dos Santos Souto ${ }^{1}$, Alexandre Valotta da Silva ${ }^{2,3}$
}

\begin{abstract}
:
The maternal exposure to high fat diet (HFD) during pregnancy and breastfeeding have been considered an important inducer of alterations in offspring normal programming, both in animals and humans, and may disturb brain development. In the present study we investigated the somatic and sensory-motor development of the offspring from rat dams fed a HFD, compared with dams fed a control diet, during pregnancy or lactation. Indicators of the body growth, physical maturation, and reflex ontogeny were evaluated. Offspring of dams fed a HFD showed reduced weight and body growth, delayed physical maturation, and delayed maturation of the physiological reflexes, such as vibrissa placing, auditory startle response, and free-fall righting. Our findings suggest that maternal HFD during pregnancy or lactation modifies somatic and neurological development of the offspring, possibly increasing the risk of neuroendocrine and neuropsychiatric disorders later in life.
\end{abstract}

Keywords: high fat diet, pregnancy, lactation, somatic growth, reflex ontogeny, offspring.

\section{RESUMO:}

A exposição materna a dieta rica em gordura (DRG) durante a gravidez e a amamentação tem sido considerada um importante indutor de alterações da programação normal da prole, em animais e humanos, e pode atrapalhar o desenvolvimento do cérebro. No presente estudo, investigamos o desenvolvimento somático e sensório-motor da prole de ratas alimentadas com uma DRG, em comparação com ratas alimentadas com uma dieta controle, durante a gravidez ou lactação. Foram avaliados indicadores de crescimento corporal, maturação física e ontogênese de reflexos. A prole de ratas alimentadas com DRG mostrou redução de peso e crescimento do corpo, atraso da maturação física e maturação tardia de reflexos fisiológicos, tais como colocação pelas vibrissas, resposta ao susto e reação de aceleração. Nossos resultados sugerem que DRG materna durante a gravidez ou lactação modifica desenvolvimento somático e neurológico da prole, possivelmente aumentando o risco para distúrbios neuroendócrinos e neuropsiquiátricos mais tarde na vida.

Palavras-chave: dieta rica em gordura, gravidez, amamentação, desenvolvimento somático, ontogênese de reflexos, prole.

The increasing prevalence of overweight and obesity is a global public health problem that affects both sexes and all age groups, especially women in reproductive age ${ }^{1}$. Currently $65 \%$ of the population in the world lives in countries in which obesity causes more deaths than malnutrition². Moreover, the induced-high fat diet (HFD) maternal obesity has risen dramatically over the past 20 years, by nearly $42 \%$ in African-Americans and 29\% in Caucasians ${ }^{3}$. Within this context, fetuses and newborns are increasingly exposed to maternal HFD which may cause problems in growth and brain development ${ }^{4}$. However, few studies have investigated the effects of maternal HFD on the brain development of the offspring $^{5,6,}$ particularly isolating or separating the periods of pregnancy and lactation. On the other hand, most studies have evaluated the effects of maternal obesity or HFD intake along gestation and lactation, hindering the identification of

${ }^{1}$ Departamento de Biociências, Universidade Federal de São Paulo, Santos SP, Brazil;

${ }^{2}$ Interdisciplinary Master in Health Sciences, Universidade Federal de São Paulo, Santos SP, Brazil;

${ }^{3}$ Instituto do Cérebro, Hospital Israelita Albert Einstein, Sao Paulo SP, Brazil.

Correspondence: Cristiano Mendes da Silva;Av D. Ana Cost 95 / Vila Mathias; 11060-001 Santos SP - Brasil; E-mail: cristiano.mendes@unifesp.br / cmendes11@hotmail.com

Conflict of interest: There is no conflict of interest to declare.

Support: This research was partly supported by Fundação de Amparo à Pesquisa do Estado de São Paulo (FAPESP 2011/17574-4;2011/17577-3 and 2011/15329-2). Received 05 June 2013; Received in final form 16 September 2013; Accepted 23 September 2013. 
the "best window" for altering developmental or physiological programming ${ }^{7,8}$ In addition, according to epidemiological and experimental studies, nutritional status and/or maternal nutrition during prenatal and early postnatal periods play an important role in epigenetic mechanisms involved in the developmental origins of non-communicable disease, such as obesity, metabolic syndrome, type 2 diabetes and cardiovascular disorders ${ }^{9-11}$, and phenotypic plasticity in response to environmental cues ${ }^{9-11}$. Furthermore, recent studies have demonstrated that the offspring from dams fed chronically with an HFD during the pregnancy and/or lactation showed changes in the hippocampal development, with decreased neurogenesis, apoptosis and neuronal differentiation ${ }^{5}$, and also neurobehavioral changes related to the serotonergic and gabaergic neurotransmitter systems ${ }^{6}$. Therefore, dietary factors may produce synaptic changes during development, similar to neurotoxins, possibly contributing to the increased incidence of neurodevelopmental disorders ${ }^{12}$. Thus, the aim of the present study was to experimentally investigate the effects of the maternal HFD during pregnancy or lactation periods on somatic and neurological development of the offspring.

\section{METHOD}

\section{Animals and diets}

Virgin female albino Wistar rats (Rattus norvegicus), (60 days old) were taken from the colony of the Department of Biosciences, Federal University of Sao Paulo (Campus Baixada Santista). Before and during the mating, the females were fed ad libitum with control diet (CD - standard laboratory chow; $52.2 \%$ carbohydrate, $23.0 \%$ protein and $14.7 \%$ lipids - Nuvilab - Nuvital Nutrientes S/A; Curitiba, Parana, Brazil). Mating was performed by housing females with adult males overnight, and pregnancy was confirmed by examining vaginal smears for the presence of sperm, designated as the day of conception, day 0 of pregnancy. Pregnant females were randomly divided and maintained in individual polypropylene cages in a room at $22^{\circ} \mathrm{C} \pm 1^{\circ} \mathrm{C}$ with lights on from 6:00 a.m. to 6:00 p.m. Thus, the dams were fed with $\mathrm{CD}$ or high fat diet (HFD - standard laboratory chow enriched with lard mainly, a few soybean oil and casein; $20.9 \%$ carbohydrate, $27.1 \%$ protein and $52.0 \%$ lipids) during the pregnancy (P - Experiment $1 ; 1^{\text {st }}$ to $21^{\text {st }}$ prenatal day) or lactation (L - Experiment $2 ; 1^{\text {st }}$ to $21^{\text {st }}$ postnatal day). The maternal body weight was recorded during the pregnancy (Figure 1A) and lactation (Figure 1B). Body weight was obtained with an electronic scale (Marte, model S-100) with a sensitivity of $0.01 \mathrm{~g}$. The chemical composition of both diets was outlined in Table 1. Twenty-four hours after birth (the birth day was considered post-natal day zero, PND 0), male and female pups born in the same date, from different mothers, were randomly distributed in litters of eight pups per dam. The pups were accessed from each reconstituted (randomized) litter, in order to prevent inbreeding. Each pup was labeled with a mark of methyl violet solution on the skin, for identification during the experiment. Seventy-two male Wistar rat pups (9 litters; 8 pups/ dam/litter), weighing between 6 and $7 \mathrm{~g}$ were distributed into four different groups according to maternal diet and development period: offspring from dams fed a CD or HFD during the pregnancy [groups (1) CD-P ( $\mathrm{n}=16)$ and (2) HFD-P (n=24) - Experiment 1] or lactation [groups (3) CD-L ( $\mathrm{n}=15)$ and (4) HFD-L ( $\mathrm{n}=17)$ - Experiment 2]. The pups were weaned on $21^{\text {st }}$ post-natal day (PND 21) and separated according to sex. After weaning all offspring were fed control diet.

The experimental design of the present study is illustrated in Figure 2. The litters (not each pup individually) were daily (PND 1 to PND 21) separated from their mothers always between 10:00 a.m. and 1:00 p.m. for evaluation of somatic growth, physical features maturation and reflex ontogeny. During this period of daily testing sessions, the pups were
A

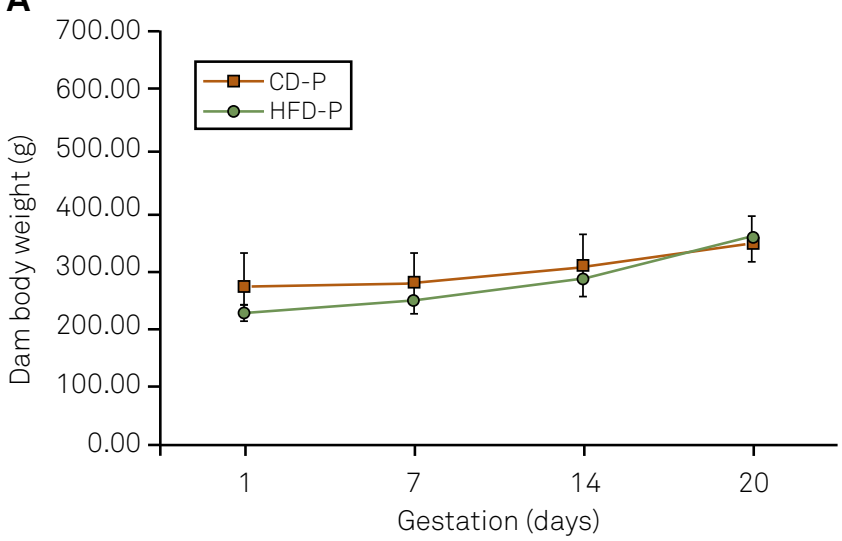

B

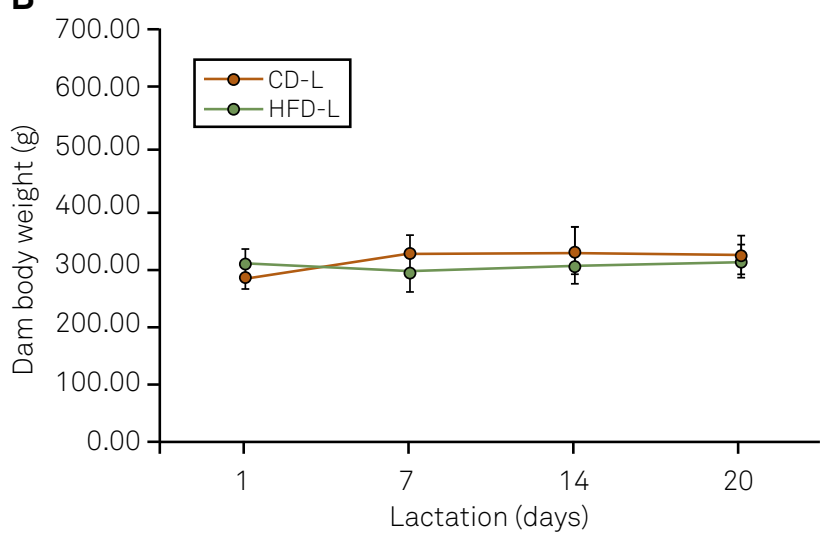

Figure 1. Body weight of rat dams during pregnancy (A) and lactation (B). Data are expressed as mean \pm SD. Abbreviations: CD-P: control diet during pregnancy; HFD-P: high fat diet during pregnancy; CD-L: control diet during lactation; HFD-L: high fat diet during lactation. For statistical analysis two-way repeated-measures ANOVA and Bonferroni's post hoc test were used. 
maintained under the same environmental conditions of maternal living, aiming to minimize the effects of maternal separation and handling. The body weight of the pups was also measured in adulthood (PND 70 to PND 95), aiming to verify the late effects of maternal HFD, during pregnancy or lactation, on nutritional status of the adult offspring. In addition,

Table 1. Content of fat, protein and carbohydrate of the control diet (CD) and of the high-fat diet (HFD) (data in $100 \mathrm{~g}$ of the diets).

\begin{tabular}{|c|c|c|c|c|c|c|}
\hline \multirow{2}{*}{ Nutrients } & \multicolumn{3}{|c|}{$C D$} & \multicolumn{3}{|c|}{ HFD } \\
\hline & $g$ & Kcal & $\% \mathrm{Kcal}$ & $g$ & Kcal & $\%$ Kcal \\
\hline Fat & 4.5 & 40.5 & 14.7 & 23.5 & 211.5 & 52.0 \\
\hline Protein & 22.7 & 90.8 & 33.0 & 27.6 & 110.4 & 27.1 \\
\hline Carbohydrate & 35.9 & 143.6 & 52.2 & 21.2 & 84.8 & 20.9 \\
\hline Total & & 274.9 & 100.0 & & 406.7 & 100.0 \\
\hline $\mathrm{Kcal} / \mathrm{g}$ & & 2.75 & & & 4.07 & \\
\hline Ingredient & & g & & & $\mathrm{g}$ & \\
\hline $\begin{array}{l}\text { Standard } \\
\text { laboratory } \\
\text { chow }\left(^{*}\right)\end{array}$ & & 100.0 & & & 50.0 & \\
\hline Sucrose & & 0.0 & & & 10.0 & \\
\hline Casein & & 0.0 & & & 20.0 & \\
\hline Soybean oil & & 0.0 & & & 2.0 & \\
\hline Lard & & 0.0 & & & 18.0 & \\
\hline Antioxidant & & - & & & 0.05 & \\
\hline Total & & 100.0 & & & 100.0 & \\
\hline
\end{tabular}

Nutritional composition of experimental diet and standard chow used during gestation or lactation. Sample analyzed=202.64 g for CD, $222.95 \mathrm{~g}$ for HFD. Laboratory reports N. 007/04/10 and 011/04/10 - Laboratory of Food Microbiology and Food Science - Federal University of Sao Paulo/ UNIFESP (Campus Vila Clementino- Sao Paulo).

(*) Balanced chow composition: calcium carbonate, corn bran, soybean meal, wheat bran, dicalcium phosphate, sodium chloride, vitamin/mineral premix, amino acids, and antioxidant. two observers, who were blinded to the treatment conditions, did all the neurodevelopmental scoring.

The experimental procedures obeyed the international norms of handling, care and experimentation with animals that were established by International Guiding Principles for Biomedical Research Involving Animals and approved by the Commission of Ethics in Animal Experimentation of the Federal University of Sao Paulo, Santos, SP, Brazil (protocol number CEP 0968/11).

\section{Somatic growth}

Somatic growth was assessed by measuring body weight and length, medio-lateral and anteroposterior head axes measurements ${ }^{13}$. These measurements were made in each animal, from PND 1 to PND 21 between 10:00 a.m. and 1:00 p.m. as follows. The body weight was measured with an electronic scale (Marte, model S-100) with a sensitivity of $0.01 \mathrm{~g}$. The longitudinal body growth (distance between the snout and the base tail), as well as medio-lateral head axis (MLHA - distance between the ear holes) and the anteroposterior head axis (APHA - distance between snout and head-neck articulation) were measured with a digital caliper (STAINLESS HARDENED, $05 \mathrm{~mm}$ precision).

\section{Physical features maturation}

The observations of the physical features ${ }^{13}$ were made and carried out daily from PND 1 to PND 21 between 10:00 a.m. and 12:00 a.m. during the suckling period. The following physical features were observed: unfolding of the external pinnae of both ears to the fully erect position; auditory conduit opening - internal auditory conduit opening of both ears; incisor eruption - the first visible and palpable crest of the lower

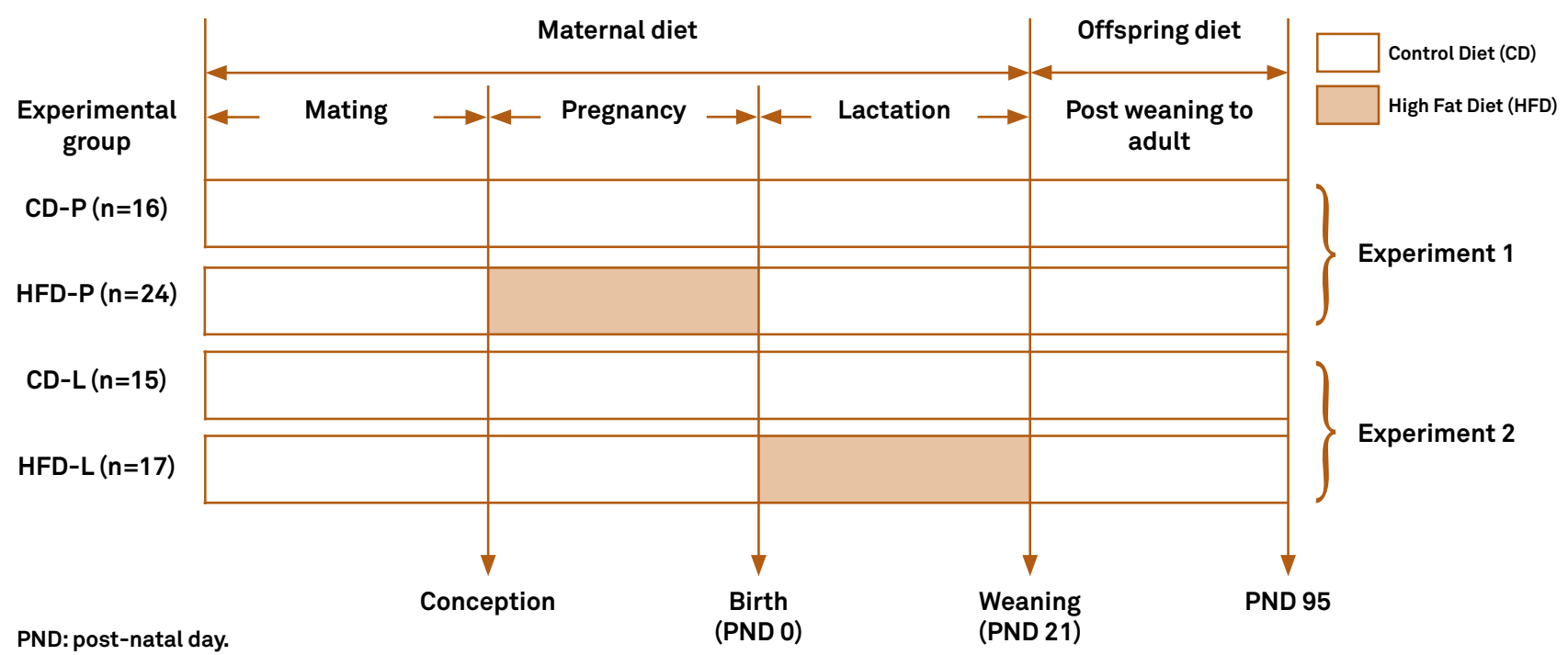

Figure 2. Experimental paradigm for maternal diets. In the CD-P and CD-L groups, dams were fed with control diet (CD) through pregnancy (P) or lactation (L). In the HFD-P group, dams were fed with high fat diet (HFD) only through pregnancy. In the HFD-P group, dams were fed with HFD only through lactation. 
incisors; and eye opening - when any visible break in the covering membrane of both eyes was detected. Maturation age of a particular feature was defined as the day when it occurred for the first time.

\section{Reflex testing}

The reflex tests ${ }^{13,14}$ were carried out daily from PND 1 to PND 21 (Table 2). Testing and observation were conducted between 10:00 a.m. and 1:00 p.m. The progress of the individuals was followed throughout the whole experiment. The time of appearance for each reflex was defined to be the first day of its occurrence. Reflex maturation was measured by registration of the age (days after birth) in which the reflex was expressed for the first time. An exception was the palm grasp, which was recorded the day of disappearance as a sign of maturation.

\section{Statistical analysis}

For statistical analysis, data related to the somatic growth (body weight and length, medio-lateral and anteroposterior head-axes) were analyzed by two-way repeated-measures ANOVA. Bonferroni's post hoc test was used. Unpaired Student's t-test was used for data related to body weight of the adult rat offspring, physical features maturation and reflex testing. All data are expressed as means \pm standard deviation(SD). The level of significance was set at $\mathrm{P}<0.05$.

\section{RESULTS}

\section{Somatic growth}

The body weight at birth of the offspring from HFD-P dams was $8 \%$ lower than controls $(6.38 \pm 0.43$ g vs. $6.93 \pm 0.69$ g, respectively) $(\mathrm{P}<0.005)$ and the body mass difference was maintained throughout suckling (Figure 3A - Experiment 1). Furthermore, pups from HFD-L dams showed smaller body weight gain $(\mathrm{P}=0.001)$ from $\mathrm{PND} 7(13.51 \pm 0.70)$ to $\mathrm{PND} 21$ (43.05 \pm 3.08$)$ when compared with controls (16.98 \pm 4.11 and $49.87 \pm 8.10$, respectively) (Figure 3B - Experiment 2). On the other hand, HFD adult offspring showed 11 to $19 \%$ (HFD-P group, $\mathrm{P}=0.001$ ) and 9 to $23 \%$ (HFD-L group) $(\mathrm{P}=0.001)$ higher body weight, when compared with controls (Figure 4 - Experiments 1 and 2).

The offsprings suckled by HFD fed dams during pregnancy showed lesser length than controls starting PND $11(78.66 \pm 1.24$ g vs. $84.12 \pm 1.78$ g, respectively) ( $\mathrm{P}=0.001)$. Reduced growth was observed throughout the lactation period ( $\mathrm{P}=0.034$ ) (Figure 3C - Experiment 1 ). In addition, the neonates breastfed by mothers exposed to HFD during lactation showed growth deficit from PND 4 to PND 5 ( $\mathrm{P}=0.001)$ and from PND 7 to PND 18 (P=0.001). However, shortly before weaning, this difference disappeared (Figure 3D - Experiment 2). The MLHA were reduced from PND 10 to PND 16 $(\mathrm{P}<0.04)$ in the offspring from HFD-P dams and from PND 4 to PND $21(\mathrm{P}=0.001)$ in the pups from HFD-L dams, compared with controls (Figure 3E and F - Experiments 1 and 2). Interestingly, in the weaning, the HFD-P offspring showed MLHA higher than controls (20.10 \pm 0.43 g vs. $19.72 \pm 0.88$ g, respectively $(\mathrm{P}=0.014)$. Besides, the APHA were also decreased throughout the suckling for both HFD offspring $(\mathrm{P}=0.001)$ (Figure 3G and $\mathrm{H}$ - Experiments 1 and 2).

\section{Physical features maturation and reflex testing}

For physical features maturation, the HFD-P offspring were delayed in respect to auditory conduit opening $(\mathrm{P}=0.001)$, and eruption of lower and upper incisors $(\mathrm{P}=0.020)$. On the other hand, all the parameters evaluated for physical features maturation in the HFD-L offspring were delayed $(\mathrm{P}=0.001)$ when compared to controls pups (Table 3 - Experiments 1 and 2 ).

Similarly, the reflex ontogeny of pups from both HFD fed dams during pregnancy or lactation were delayed in most reflexes $(\mathrm{P}<0.002)$, vibrissa placing, startle response, free fall

Table 2. Procedures for detection of reflexes maturation.

\begin{tabular}{|c|c|c|}
\hline Reflex & Stimulus & Response \\
\hline Palmar grasp & $\begin{array}{l}\text { Palm of forepaw stroked gently with a paper } \\
\text { clip. }\end{array}$ & $\begin{array}{l}\text { Flexion of digits. As a maturation response, any or a very slight flexion } \\
\text { must be seen. For this reflex, the disappearance date is registered. }\end{array}$ \\
\hline Righting & Rat placed on back on a flat surface. & $\begin{array}{l}\text { It turns over, to rest in ventral decubitus, with the four paws on the } \\
\text { surface, in } 10 \mathrm{~s} \text {. }\end{array}$ \\
\hline Vibrissa placing & $\begin{array}{l}\text { Rat held by the tail, head facing an edge of } \\
\text { bench, vibrissa just touching vertical surface. }\end{array}$ & $\begin{array}{l}\text { Lifts head and extends forepaws in the direction of the bench, making } \\
\text { oriented "walking" movements to go far from the edge, in } 10 \mathrm{~s} \text {. }\end{array}$ \\
\hline Cliff avoidance & $\begin{array}{l}\text { Rat put on edge of bench, with nose and } \\
\text { forefeet just over edge. }\end{array}$ & $\begin{array}{l}\text { Withdrawal of head and both forefeet from edge, moving away from } \\
\text { "cliff", in } 10 \mathrm{~s} \text {. }\end{array}$ \\
\hline Auditory startle & $\begin{array}{l}\text { Sudden sound stimulus by percussion with } \\
\text { a metallic stick in a metal surface. }\end{array}$ & $\begin{array}{l}\text { Body retraction, with a transitory immobility. The stimulus was given } \\
\text { twice in each test, with a 1-min interval. }\end{array}$ \\
\hline Negative geotaxis & $\begin{array}{l}\text { Rat placed with head downwards, on a } 45^{\circ} \mathrm{C} \\
\text { - slope. }\end{array}$ & Turns to face up the slope, at least $\geq 130^{\circ} \mathrm{C}$, in $10 \mathrm{~s}$. \\
\hline Free-fall righting & $\begin{array}{l}\text { Rat held by the paws, back downwards, is } \\
\text { dropped from } 30 \mathrm{~cm} \text { onto cotton - wool pad. }\end{array}$ & $\begin{array}{l}\text { Turns body in mid-air, to land on all fours. All legs must be free of } \\
\text { body on landing. }\end{array}$ \\
\hline
\end{tabular}


A

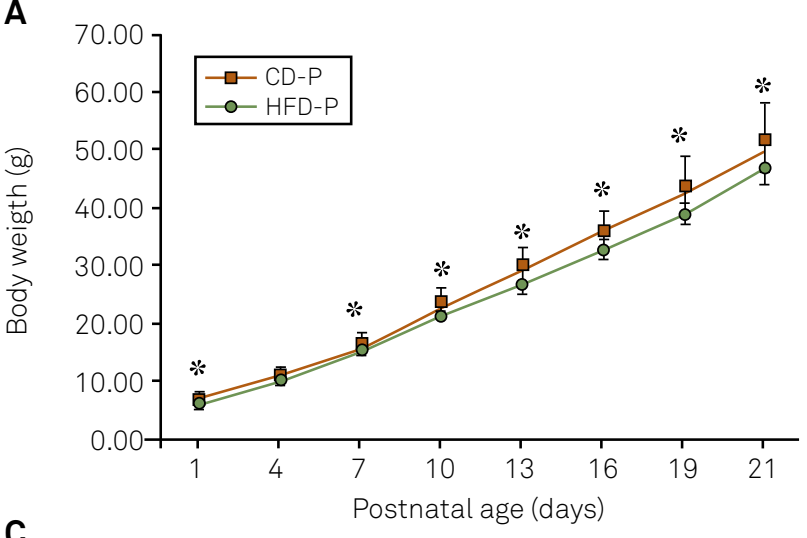

C

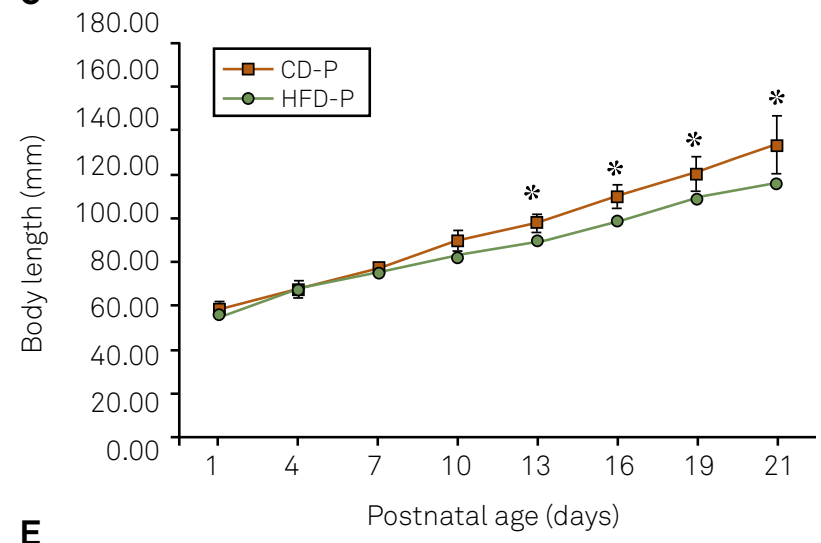

E

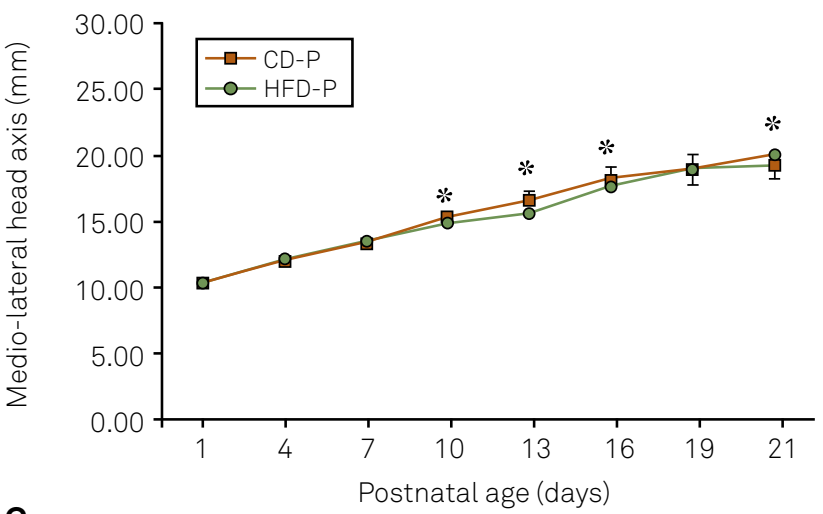

G

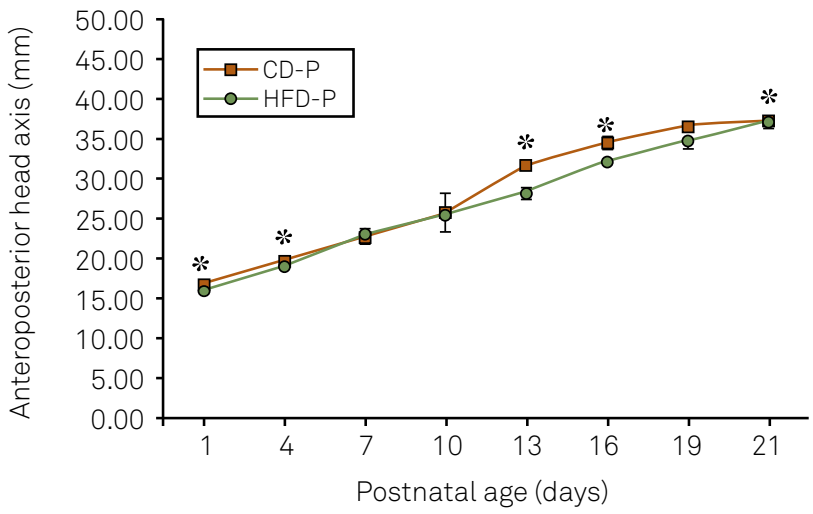

B

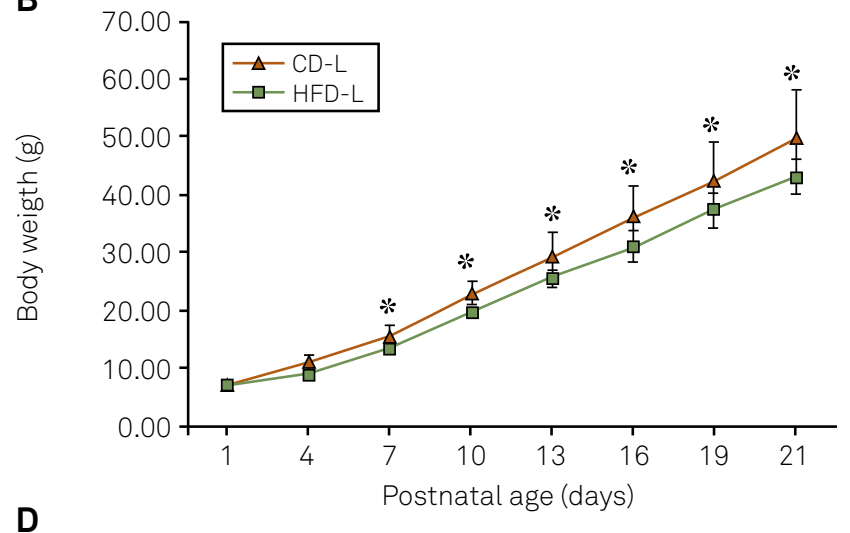

D

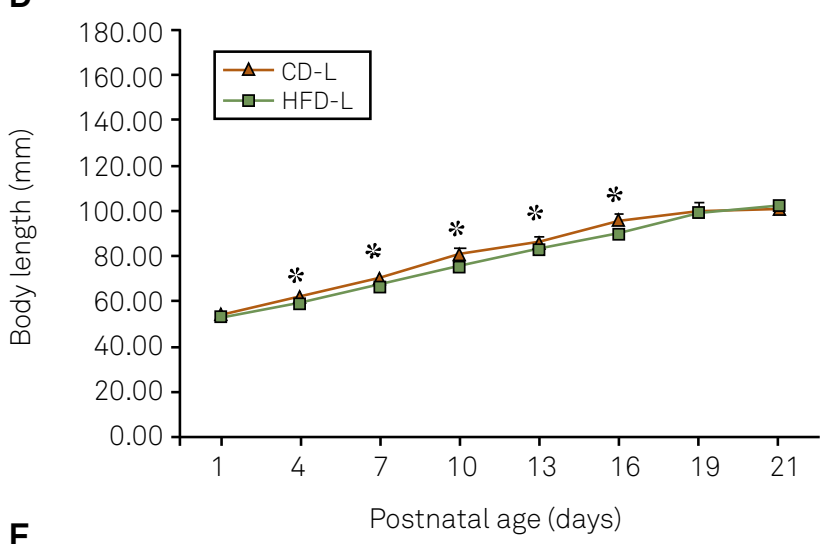

$\mathbf{F}$

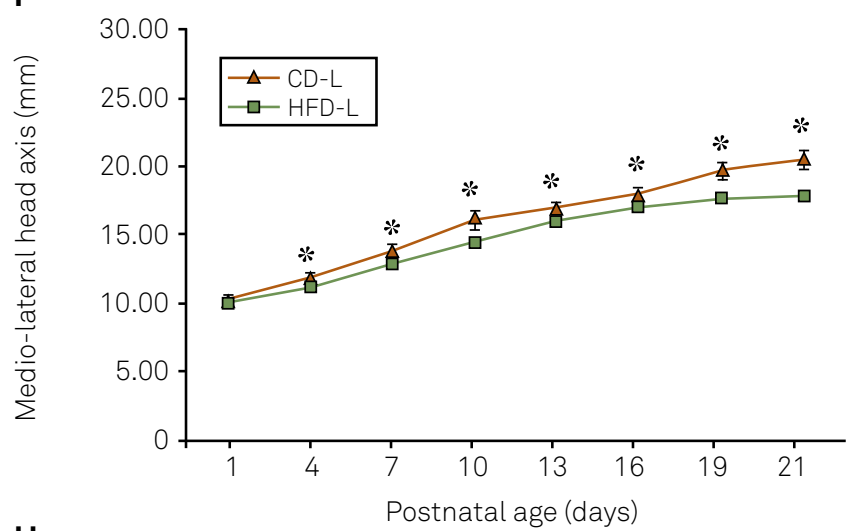

H

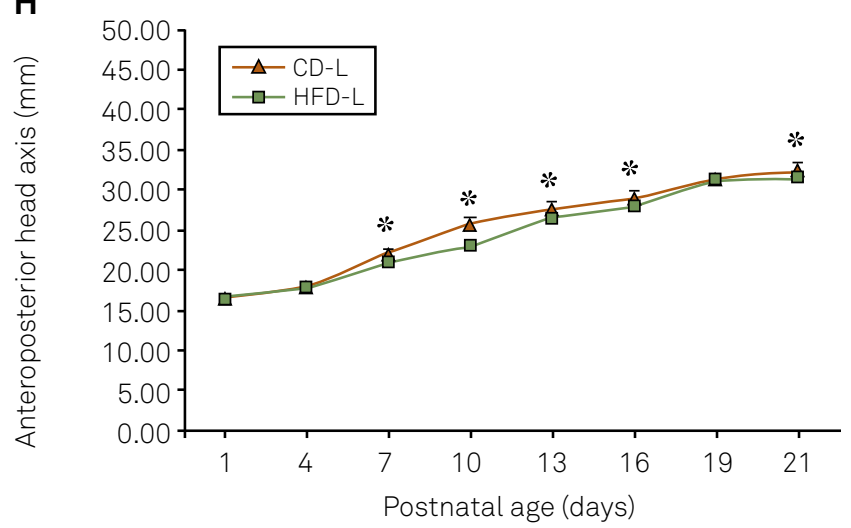

Figure 3. Body weight ( $A$ and $B$ ) and length ( $C$ and $D)$, medio-lateral ( $E$ and $F$ ) and anteroposterior ( $G$ and $H$ ) head axes of rats offspring from dams fed a high fat diet (HFD - 52.0\% fat) or dams fed a control diet (CD - 14.7\% fat) during the pregnancy (A, C, $\mathrm{E}$ and $\mathrm{G}$ ) or lactation (B, D, F and H). The results are presented as mean \pm standard deviation (SD). Abbreviations: P: pregnancy; L: lactation. For statistical analysis were used two-way repeated-measures ANOVA and Bonferroni's post hoc test. To body weight: ${ }^{*} P<0.03$ vs. CD-P group and ${ }^{*} P<0.002$ vs. CD-L group; To body length: ${ }^{*} P<0.05$ vs. CD-P group and ${ }^{*} P<0.03$ vs. CD-L group; To mediolateral head axis: ${ }^{*} P<0.01$ vs. CD-P group and ${ }^{*} P<0.002$ vs. CD-L group; To anteroposterior head axis: ${ }^{*} P<0.05$ vs. CD-P group and ${ }^{*} \mathrm{P}<0.03$ vs. CD-L group. 
righting, palm grasp (only in HFD-P offspring) and negative geotaxis (only in HFD-L offspring) when compared to controls. Righting and cliff avoidance reflexes were not altered (Table 4 - Experiments 1 and 2).

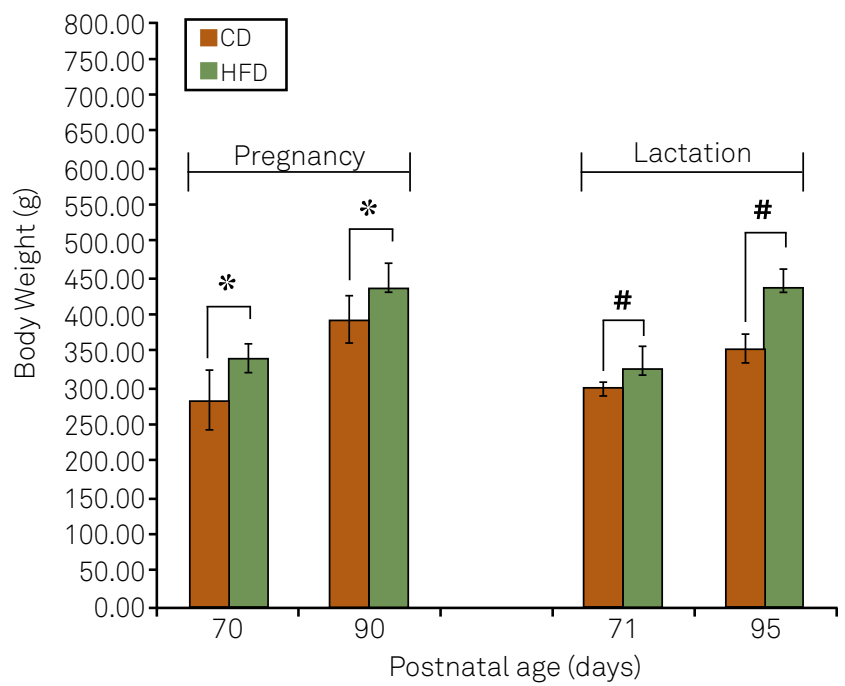

Figure 4. Body weight of the adult rat offspring from dams fed a high fat diet (HFD - 52.0\% fat) or dams fed a control diet (CD - 14.7\% fat). The results are presented as mean \pm standard deviation (SD). Abbreviations: P: pregnancy; L: lactation. All by unpaired Student's t-test. ${ }^{*} \mathrm{P}<0.01$ vs. CD-pregnancy group and \# $P=0.001$ vs. CD-lactation group.

\section{DISCUSSION}

In the present study, maternal HFD during the pregnancy (Experiment 1) or lactation (Experiment 2) induced changes in somatic and neurological development, promoting: 1 . Reduced body weight and length early in life; 2 . Overweight later in life; 3 . Altered head growth; 4. Delayed reflex ontogeny; and 5. Delayed acquisition of mature developmental patterns of physical features. These changes are similar to those observed in the offspring of undernourished mothers ${ }^{14}$ and opposite to those observed in dams with overnutrition ${ }^{15}$.

Several clinical and experimental studies have shown that prenatal (intrauterine) and early postnatal maternal nutrition have a significant role on food intake, body weight and energy homeostasis of the offspring ${ }^{16,17}$. Pups of dams fed HFD during pregnancy and lactation showed low birth weight and reduced body weight during lactation, compared with controls ${ }^{16,18}$. According to Niculesco and Lupu [5], high fat diet-induced maternal obesity has impaired the intrauterine growth as determined by the low weight fetus. The results of the present study are in line with previous investigations, since the HFD offspring had reduced weight at birth (only HFD-P; Experiment 1) and throughout lactation (HFD-P and HFD-L; Experiments 1 and 2).

Moreover, the HFD pups in both experiments showed altered development of body length and cranial axes. Recent experimental studies have demonstrated the influence of

Table 3. Maturation age (days) for physical features of rats offspring from dams fed a high fat diet (HFD - 52.0\% fat) or dams fed a control diet (CD - 14.7\% fat) during the pregnancy $(P)$ or lactation $(L)$. The results are presented as mean \pm standard deviation (SD). Abbreviations: P: pregnancy; L: lactation. ${ }^{*}<0.03$ vs. CD-P group, by unpaired Student's t-test; ${ }^{P}<0.002$ vs. CD-L group, by unpaired Student's t-test.

\begin{tabular}{lccccc} 
& \multicolumn{3}{c}{ Groups } \\
\cline { 2 - 3 } & \multicolumn{2}{c}{ Experiment 1 } & & \multicolumn{2}{c}{ Experiment 2 } \\
\cline { 2 - 3 } \cline { 5 - 6 } & $\mathrm{CD}-\mathrm{P}(\mathrm{n}=16)$ & $\mathrm{HFD}-\mathrm{P}(\mathrm{n}=24)$ & & $\mathrm{CD}-\mathrm{L}(\mathrm{n}=15)$ & $\mathrm{HFD}-\mathrm{L}(\mathrm{n}=17)$ \\
\hline Ear unfolding & $4.25 \pm 0.68$ & $4.13 \pm 0.61$ & & $4.00 \pm 0.00$ & $5.00 \pm 0.49^{\#}$ \\
Auditory conduit opening & $12.50 \pm 0.52$ & $13.00 \pm 0.00^{*}$ & & $12.60 \pm 0.51$ & $14.12 \pm 0.49^{\#}$ \\
Eruption of the incisors & $10.56 \pm 0.81$ & $11.50 \pm 1.10^{*}$ & & $9.00 \pm 1.03$ & $10.24 \pm 0.44^{\#}$ \\
Eyes opening & $14.63 \pm 0.81$ & $14.79 \pm 0.41$ & & $14.00 \pm 0.00$ & $15.18 \pm 0.73^{\#}$ \\
\hline
\end{tabular}

Table 4. Reflex maturation age (days) of rats offspring from dams fed a high fat diet (HFD - 52.0\% fat) or dams fed a control diet (CD - 14.7\% fat) during the pregnancy (P) or lactation (L). The results are presented as mean \pm standard deviation (SD). Abbreviations: P: pregnancy; L: lactation..P<0.002 vs. CD-P group, by unpaired Student's t-test; \#P<0.002 vs. CD-L group, by unpaired Student's t-test.

\begin{tabular}{|c|c|c|c|c|}
\hline \multirow{3}{*}{ Reflexes } & \multicolumn{4}{|c|}{ Groups } \\
\hline & \multicolumn{2}{|c|}{ Experiment 1} & \multicolumn{2}{|c|}{ Experiment 2} \\
\hline & $C D-P(n=16)$ & HFD-P $(n=24)$ & $C D-L(n=15)$ & HFD-L $(n=17)$ \\
\hline Palm grasp & $7.63 \pm 1.20$ & $10.46 \pm 2.93^{\star}$ & $12.60 \pm 2.92$ & $10.59 \pm 2.98$ \\
\hline Righting & $5.13 \pm 1.45$ & $5.38 \pm 1.50$ & $5.60 \pm 2.41$ & $6.00 \pm 1.62$ \\
\hline Vibrissa placing & $10.06 \pm 0.68$ & $13.42 \pm 1.25^{\star}$ & $9.87 \pm 0.92$ & $12.41 \pm 2.50^{\#}$ \\
\hline Cliff avoidance & $13.25 \pm 3.57$ & $13.58 \pm 2.52$ & $12.47 \pm 0.83$ & $11.06 \pm 4.18$ \\
\hline Negative geotaxis & $12.46 \pm 2.13$ & $12.46 \pm 2.13$ & $13.33 \pm 1.68$ & $17.18 \pm 1.07^{\#}$ \\
\hline Auditory startle response & $12.50 \pm 0.52$ & $13.00 \pm 0.00 *$ & $12.00 \pm 0.76$ & $14.00 \pm 0.00^{\#}$ \\
\hline Free fall righting & $12.88 \pm 1.86$ & $14.92 \pm 1.06 *$ & $12.00 \pm 1.13$ & $16.53 \pm 1.70^{\#}$ \\
\hline
\end{tabular}


prenatal and early postnatal maternal nutrition on the offspring's body and cranial growth ${ }^{15}$. In this context, pups from dams fed low protein diet showed reduced skull axes ${ }^{19}$, whereas the offspring from mother fed with hypercaloric vegetable oils supplemented diets during gestation and lactation showed shortened body length ${ }^{15}$. Thus, during gestation and/or lactation, the high saturated fat intake may be as harmful to the developing pups as undernutrition. In addition, the dam rats fed with lard supplemented diets did not show significant increases in body weight during the pregnancy or suckling, despite more intakes of calories from fat in the HFD. Other results have suggested that pregnant rats on a fat-enriched diet reduce their ingestion to maintain similar caloric intake compared with controls ${ }^{20}$. Keesey and Hirvonen ${ }^{21}$ proposed the existence of a "body weight setpoint" in rodents and humans so that body weight decrease or increase is corrected by altering food intake and energy expenditure to maintain the target body weight. Although this weight-control mechanism was not investigated in the present study, it could explain the lack of significant effects on dam body weight.

The growth deficiencies (body weight and length, and head axes) that we observed in offspring from dams fed HFD could be due to abnormalities of mammary gland function. In fact, Flint et al. observed that dams fed HFD showed impaired mammary development and lactogenesis $^{22}$. HFD-induced changes observed in mammary gland include: 1. Abnormalities in alveolar development; 2. Lipid accumulation in the secretory epithelial cells, indicative of an absence of copious milk secretion; 3. Decreased mRNA expression for $\beta$-casein and $\alpha$-lactalbumin immediately postpartum; and 4. Reduced breast milk volume, a compensation mechanism due to high-energy $\operatorname{diet}^{22}$. These findings suggest that, despite access to high-energy diet, dams fed HFD produce an insufficient volume of breast milk which is also deficient in proteins. These abnormalities may underlie the impaired development of the offspring.

Interestingly, we observed that the offspring of dams fed HFD showed reduced body weight curves in early life and overweight later in life. Several studies support this finding. Pups from female rats fed HFD during pregnancy and suckling had low birth weight and reduced plasma leptin in PND 2 , but became obese and showed increased plasma leptin in adulthood ${ }^{23}$. Moreover, adult offspring from mothers fed HFD (during the same periods) showed hypertension, hypercholesterolemia, hyperphagia, overweight, increased visceral fat, liver weight, blood glucose and triglycerides ${ }^{7-11}$. These abnormalities could be associated with alterations of hypothalamic development. The central role of the hypothalamus in controlling food intake is well recognized. Nevertheless, the hypothalamus has been considered to have a role in altering physiological programming, particularly associated to early nutritional manipulation ${ }^{17}$. Furthermore, the prenatal and early postnatal periods are critical for regulation of expression of hypothalamic orexigenic neuropeptides and their receptors, which also can be programmed by factors related to maternal diet ${ }^{24}$. Therefore we believe that overweight in the adult HFD offspring observed in the present study may be associated with alterations of hypothalamic development.

The offspring of dams fed HFD also showed some adverse effects in physical and neurobehavioral outcomes, including altered development of all studied physical features (except ear unfolding and eyes opening to HFD-P group), palm grasp reflex (only HFD-P group), vibrissa placing, startle response, negative geotaxis (only HFD-L group), and free fall righting. These findings suggest impairment of sensory-motor system and may reflect a vulnerability of the developing brain to changes in maternal diet. Accordingly, many authors have shown that the importance of maternal overnutrition for fetal and newborn brain development is increasingly recognized. Studies have suggested that maternal obesity or maternal exposure to HFDs, during pregnancy and lactation periods, may permanently alter brain structure and function in the offspring, ${ }^{5,6}$ and this change could affect the sensorymotor development.

Moreover, the results of the present work corroborate those of Soares et al. ${ }^{25}$ that observed delayed somatic and reflex development in suckling rats from dams fed with ketogenic diet associated with lack of protein. In other study, the offspring from dams fed with vegetable oils supplemented diets (soy and sunflower oils) during gestation and lactation showed delayed puberty onset and poor cliff avoidance behavior $^{15}$, partly corroborating our results. The authors of that study observed some beneficial effects on physical and reflex maturation ${ }^{15}$. However, the beneficial effects were associated with the maternal high intake of polyunsaturated fatty acids (w-6 and w-3), unlike our findings, because we used lard (saturated fatty acids) as source of fat. These results suggest that different types of maternal HFD may produce different effects on offspring development.

The placenta plays a crucial role in the transport of bioactive molecules from mother to fetus ${ }^{26}$. Maternal lipids can be transferred across the placenta and are accumulated in the brain and other organs during fetal development ${ }^{27}$. On the other hand, also more interestingly, changes in dietary fat content modify milk lipid content and daily milk lipid production in lactating animals ${ }^{28}$. It seems that in both situations the offspring's brain development may be vulnerable to the effects of lipotoxicity or lipid peroxidation induced by maternal high-fat intake. ${ }^{3}$ In addition, the lipotoxicity resulting from maternal HFD is capable of activating a number of stress signaling cascades including pro-inflammatory cytokines and oxidative stress ${ }^{3,8}$, which can damage the neurodevelopment of the offspring 5 . In this context, some experimental studies have demonstrated: 1 . Reduced proliferation of hippocampal dentate gyrus progenitor cells ( $\mathrm{pH} 3$-labeled 
cells) $)^{5} ; 2$. Decreased apoptosis and neuronal differentiation in specific hippocampal areas ${ }^{5}$; and 3. Morphofunctional changes of gabaergic and serotonergic neurotransmitter systems ${ }^{6}$. In studies Sullivan et al. ${ }^{29}$ Raibstein-and Peleg et al. ${ }^{6}$ were demonstrated up-regulation of the 5-HT1A inhibitory autoreceptor in the offspring of dams fed HFD. In the first ${ }^{29}$, the authors observed increased expression of $5-\mathrm{HT}^{1 \mathrm{~A}}$ receptors in the dorsal raphe nucleus in nonhuman primates. On the other hand, in the second study researchers showed expression high of $5-\mathrm{HT}^{1 \mathrm{~A}}$ in ventral hippocampus. These neurochemical changes can promote suppression of the serotonergic system in the offspring HFD, since the $5-\mathrm{HT}^{1 \mathrm{~A}}$ auto-receptor inhibits the release of serotonin ${ }^{6,29}$ and thus perhaps result in the sensory and motor disorders found in the present paper. This set of results and findings indicate that prenatal and/or early postnatal exposure to HFD may impair brain development, possibly affecting sensory and motor functions.

Results of the present study suggest that lipotoxicity induced by maternal HFD may affect the cerebellum and vestibular system. In fact, the reflex ontogeny reflects sensory-motor development and integrity of vestibulocerebellar system, which integrate exteroceptive input (vibrissae) and locomotor output ${ }^{30}$, and may be affected by nutritional manipulations ${ }^{31}$. In general, since neonatal reflexes may be considered as an index of brain maturation, the present findings reinforce the notion that maternal nutrition affects prenatal and early postnatal mechanisms responsible for normal brain development ${ }^{14,15,25}$. In another hypothesis, perhaps the delay in the somatic and neurobehavioral development of the offspring HFD may be related to neural stem cells (NSCs) loss due to the effect of pro-inflammatory induced by early exposure to high-fat diet, as evidenced hypothalamic NSCs ${ }^{32}$.

In summary, the present study demonstrates that maternal HFD during gestation or lactation impaired similarly the somatic and neurological development of the offspring, without significant differences between prenatal and postnatal manipulation. This neurodevelopmental damage may reflect in neuropsychiatric disorders later in life, such as psychomotor, behavioral and cognitive disturbances ${ }^{5,6,25}$. Nevertheless, further studies are needed to better elucidate the underlying neural and molecular mechanisms involved in this process.

\section{ACKNOWLEDGMENTS}

The authors thank Mrs. Fábio Tadeu Montesano and Felipe Granado de Souza for technical assistance in statistical analysis.

\section{References}

1. Kim SY, Dietz PM, England L, Morrow B, Callaghan WM. Trends in prepregnancy obesity in nine states, 1993-2003. Obesity (Silver Spring) 2007;15:986-993.

2. World Health Organization Obesity and overweight. (http://www.who.int/ mediacentre/factsheets/fs311/en/) World Health Organization 2011.

3. Dong M, Zheng Q, Ford SP, Nathanielsz PW, Ren J. Maternal obesity, lipotoxicity and cardiovascular diseases in offspring. J Mol Cell Cardiol 2013;55:111-116.

4. Sebert S, Sharkey D, Budge H, Symonds ME. The early programming of metabolic health: is epigenetic setting the missing link? Am J Clin Nutr 2011;94(Suppl 6):S1953-S1958.

5. Niculescu MD, Lupu DS. High fat diet-induced maternal obesity alters fetal hippocampal development. Int J Dev Neurosci 2009;27:627-633

6. Peleg-Raibstein D, Luca E, Wolfrum C. Maternal high-fat diet in mice programs emotional behavior in adulthood. Behav Brain Res 2012;233:398-404.

7. Oliveira TW, Leandro CG, de Jesus Deiró TC, et al. A perinatal palatable high-fat diet increases food intake and promotes hypercholesterolemia in adult rats. Lipids 2011;46:1071-1074.

8. Ashino NG, Saito KN, Souza FD, et al. Maternal high-fat feeding through pregnancy and lactation predisposes mouse offspring to molecular insulin resistance and fatty liver.J Nutr Biochem 2012;23:341-348.

9. Barker DJ. Fetal programming of coronary heart disease. Trends Endocrinol Metab 2002;13:364-368.

10. Gluckman PD, Hanson MA, Beedle AS, Raubenheimer D. Fetal and neonatal pathways to obesity. Front Horm Res 2008;36:61-72.
11. Hanson M, Gluckman P. Developmental origins of non-communicable disease: population and public health implications. Am J Clin Nutr 2011;94(Suppl 6): S1754-S1758.

12. Slotkin TA, Wrench N, Ryde IT, Lassiter TL, Levin ED, Seidler FJ. Neonatal parathion exposure disrupts serotonin and dopamine synaptic function in rat brain regions: modulation by a high-fat diet in adulthood. Neurotoxicol Teratol 2009; 31:390-399.

13. Deiró TC, Manhães-de-Castro R, Cabral-Filho JE, et al. Sertraline delays the somatic growth and reflex ontogeny in neonate rats. Physiol Behav 2006;87:338-344.

14. Barros KM, Manhães-De-Castro R, Lopes-De-Souza S, et al. A regional model (Northeastern Brazil) of induced malnutrition delays ontogeny of reflexes and locomotor activity in rats. Nutr Neurosci 2006;9:99-104.

15. Santillán ME, Vincenti LM, Martini AC, et al. Developmental and neurobehavioral effects of perinatal exposure to diets with different omega-6:omega-3 ratios in mice. Nutrition 2010;26:423-431.

16. Bayol SA, Farrington SJ, Stickland NC. A maternal 'junk food' diet in pregnancy and lactation promotes an exacerbated taste for 'junk food' and a greater propensity for obesity in rat offspring. Br J Nutr 2007;843-851-898.

17. Orozco-Solís R, Matos RJ, Guzmán-Quevedo O, et al. Nutritional programming in the rat is linked to long-lasting changes in nutrient sensing and energy homeostasis in the hypothalamus. PLoS One 2010;5:13537.

18. Rolls BJ, Rowe EA. Pregnancy and lactation in the obese rat: effects on maternal and pup weights. Physiol Behav 1982;28:393-400. 
19. Miller JP, German RZ. Protein malnutrition affects the growth trajectories of the craniofacial skeleton in rats. J Nutr 1999;129:2061-2069.

20. Taylor PD, Khan IY, Lakasing L, et al. Uterine artery function in pregnant rats fed a diet supplemented with animal lard. Exp Physiol 2003;88:389-398.

21. Keesey RE, Hirvonen MD. Body weight set-points: determination and adjustment. J Nutr 1997;127(Suppl):S1875-S1878.

22. Flint DJ, Travers MT, Barber MC, Binart N, Kelly PA. Diet-induced obesity impairs mammary development and lactogenesis in murine mammary gland. Am J Physiol Endocrinol Metab. 2005;288:1179-87.

23. Howie GJ, Sloboda DM, Kamal T, Vickers MH. Maternal nutritional history predicts obesity in adult offspring independent of postnatal diet.J Physiol 2009;587:905-915.

24. Taylor PD, Poston L. Developmental programming of obesity in mammals. Exp Physiol 2007;92:287-298.

25. Soares AK, Guerra RG, de Castro ML, et al. Somatic and reflex development in suckling rats: effects of mother treatment with ketogenic diet associated with lack of protein. Nutr Neurosci 2009;12:260-266.
26. Jones, HN, Powell TL and Jansson T. Regulation of placental nutrient transport-a review. Placenta 2007;28:763-774.

27. Innis SM. Essential fatty acid transfer and fetal development. Placenta 2005;26:70-75.

28. Del Prado M, Delgado G, Villalpando S. Maternal lipid intake during pregnancy and lactation alters milk composition and production and litter growth in rats. J Nutr 1997;127:458-446.

29. Sullivan EL, Grayson B, Takahashi D, et al. Chronic consumption of a high-fat diet during pregnancy causes perturbations in the serotonergic system and increased anxiety-like behavior in nonhuman primate offspring. J Neurosci 2010;30:3826-3830.

30. Sebert S, Sharkey D, Budge H, Symonds ME. The early programming of metabolic health: is epigenetic setting the missing link? Am J Clin Nutr 2011;94(Suppl 6): S1953-S1958.

31. Koros C, Boukouvalas G, Gerozissis K, Kitraki E. Fat diet affects leptin receptor levels in the rat cerebellum. Nutrition 2009;25:85-87.

32. Li J, Tang $Y$, Cai D. IKK $/ N F-\kappa B$ disrupts adult hypothalamic neural stem cells to mediate a neurodegenerative mechanism of dietary obesity and pre-diabetes. Nat Cell Biol 2012;14:999-1012. 